\title{
JOSÉ BALZA, LA ESCRITURA COMO MEDIO DE CONOCIMIENTO
}

\author{
POR \\ Josefina BERRIZBEITIA \\ Universidad Simón Bolivar
}

José Balza es uno de los narradores venezolanos que en las últimas décadas ha contribuido significativamente a modificar el panorama literario nacional. Esta narrativa más reciente se caracteriza por una experimentación que aborda tanto la relación con la realidad como la que mantiene con el hecho estético en sí. Definir actitudes precisas con respecto a lo literario, expresar una conciencia más aguda del hombre y su entorno parecen ser algunas de las provisiones de un grupo de escritores que desde los años sesenta viene realizando en Venezuela un trabajo continuo en cuanto a creación y crítica se refiere. Las posibilidades expresivas del lenguaje, la autonomía del texto literario, un acercamiento ontológico a la realidad son elementos nuevos dentro de la tradición racionalista que caracterizaba hasta entonces la interpretación de lo real. El trabajo de José Balza constituye un valioso aporte no sólo en esta revisión de la trayectoria literaria venezolana: las promesas miríficas de un realismo que se mostró con frecuencia insuficiente e ineficaz para comprender y expresar la realidad; sirio sobre todo en la construcción de una obra cuya concepción nueva de la escritura le permitirá ya no explicar sino cuestionar esa realidad.

José Balza nace en 1941 en el territorio del Delta Amacuro. Su infancia transcurre en esta región de la desembocadura del Orinoco y allí realiza Balza sus primeras lecturas literarias. Sus estudios secundarios y universitarios (en psicología) lo llevarán a Caracas donde se precisa paralelamente su interés por la literatura. Trabaja como psicólogo en varias insitituciones nacionales pero sus conocimientos literarios lo conducen finalmente a la docencia y a la investigación. Ha sido profesor en varias universidades nacionales y extranjeras. Además de numerosos artículos publicados en revistas y suplementos literarios, Balza publica en 1965 una primera novela, Marzo anterior, que obtiene el Premio Municipal de Prosa; en 1968 aparece su segunda novela, Largo; en 1974, Setecientas palmeras plantadas en el mismo lugar; en 1977, D; y en 1982, su quinta novela, Percusión. Ha publicado igualmente cuatro volúmenes de cuentos: Ejercicios narrativos, en 1967; Órdenes, en 1970; Un rostro absolutamente, en 1982, y La mujer de espaldas, en 1986. El fundamento de su teoría literaria se encuentra en Narrativa: instrumental y observaciones (1969), Los cuerpos del sueño (1976) y Este mar narrativo (1987). Es autor de tres obras críticas: Proust (1969), Lectura transitoria (sobre la poesia de Rafael Cadenas) (1973) y Transfigurable (1983). 


\section{CARÁCTER EXPERIMENTAL DE UNA NARRATIVA}

Balza forma parte de una generación de escritores que hereda las enseñanzas de la nueva novela latinoamericana en su intento por modificar estructuras narrativas tradicionales y por crear nuevas formas de percibir y traducir el mundo. Este proyecto se intensifica en un escritor como Balza en quien la escritura deja de ser instrumento para convertirse en el único espacio de fundación de la realidad donde el escritor se crea a sí mismo a la vez que inventa el mundo. La distancia entre realidad y ficción se acorta porque el escritor ya no se asume como el punto de enlace de irradiación que proyecta formas y hace inteligible la experiencia. El los "ejercicios narrativos", término que utiliza para denominar sus escritos, Balza manifiesta esta nueva posición frente a la actividad literaria. Así lo señala Julio Ortega:

... el narrador quiere apresar los más diversos niveles de realidad en el único nivel que posee: la escritura. Por otro lado con esta estructura el narrador revela sus propias tensiones con la realidad, porque en la nueva literatura son las formas y su ordenamiento, la estructura del relato, lo que anuncia su visión del mundo. Y su cuestionamiento del género es también una crítica de esa visión. ${ }^{1}$

Interrogar la experiencia y doblegar el lenguaje para intentar la nueva exploración que se impone hacen de la iniciativa de Balza un compromiso diferente entre creación y vida: la belleza ya no es un objetivo externo al artista, es la realización de su propia existencia. La literatura se vuelve entonces proceso de conocimiento. De allí que los ejercicios de Balsa registren continuamente el encuentro entre una conciencia y el mundo. Su óptima narrativa es la de una introspección que puede dar cuenta del descubrimiento de la realidad, de la aprehensión del mundo y al mismo tiempo, de la conciencia de este fenómeno. De hecho el carácter de fenómeno mental que tiene esta escritura explica la ambivalencia del texto que a su vez remite a la ambivalencia inherente a toda percepción humana. Las novelas de Balza proponen como única realidad la de una subjetividad en constante auto-observación:

En el [estilo] de José Balza la narración indirecta se ve incesantemente interrumpida por la participación del narrador, que a su vez es otro personaje más, y así se crea una suerte de conciencia que cuenta en función de los otros y al mismo tiempo reflexiona sobre lo que cuenta (la obra explicada dentro de la obra). De esta manera, en todos estos relatos la distancia entre la cosa narrada y el narrador se acorta sensiblemente e, insensiblemente, entramos en un juego de espejos donde se diluye toda objetividad y toda subjetividad. El escritor narra pero es también personaje; propone una ficción que es su única realidad. De este modo, nos da no sólo una visión más compleja y dinámica del mundo real; su verdadero rostro se va perfilando igualmente dentro de esa visión. ${ }^{2}$

\footnotetext{
1 Julio Ortega, La contemplación y la fiesta (Caracas: Monte Ávila Editores, 1969) 12.

${ }^{2}$ G. S., "En la línea más cercana", Revista Imagen (Caracas, 1-15 de mayo de 1968).
} 


\section{LA ESCRITURA COMO FENÓMENO}

Michel Butor alguna vez habló de la novela como "el campo fenomenológico por excelencia". Las novelas de José Balza parecen merecer especialmente esta denominación. Siguiendo la tradición del nouveau roman, Balza le asigna a la percepción una responsabilidad definitiva en la construcción de lo real: su narración parece surgir de este contacto directo con las cosas que se le presentan a la conciencia y a la vez del reconocimiento de este encuentro. Este punto de vista permite entender cómo lo que existe se vuelve cognoscible para el hombre. De esta manera las percepciones articulan el mundo pero también la mirada sobre ese mundo y por consiguiente las novelas que intentan traducir esa mirada. La conciencia asigna forma a la realidad. La conciencia narrativa asigna estructuras a la novela.

\section{El CUERPO NOVELESCO}

Las exigencias de Balza en cuanto al trabajo literario giran alrededor de un núcleo esencial que es justamente el de la construcción literaria, el de la forma narrativa. En una intervención en la New York University en 1980 (titulada "Un testigo y un hacedor de la literatura venezolana"), Balza desarrolla la idea de la importancia estructural del tiempo y el espacio narrativos y subraya el hecho de que la originalidad de una obra se manifiesta antes que todo en su realización de conjunto:

Siglos de una fe en la razón del hombre, y en la continuidad del relato van a ser afectados por teóricos como Freud, Bergson, Einstein. Así la novela, desde Proust, luego Joyce, Faulkner, Dos Passos, etc., traerán una visión más acertada sobre los ejes secretos de la narrativa. En ellos, en los descubridores, encontraré lo que yo considero la verdad más íntima del narrador: su capacidad para componer, para convertir en un cuerpo flexible, móvil y sin embargo rígidamente coherente, el contexto de la novela o del cuento. El secreto reside en la composición, en el uso de los ejes estructurales: el espacio y el tiempo narrativos ... mientras el autor parezca menos estricto - por sus libertades anecdóticas, por sus delirios estilísticos- los ejes del tiempo y espacio narrativos impondrían una armónica matemática y secreta concisión: la forma, la composición. Así, después de auscultar la anécdota, los estilos y sus recursos, comprendí que sólo la composición, la vertebración formal, el cuerpo técnico del relato, esconde el secreto máximo del hacedor de ficciones. "Hacer" literatura me reveló esas vinculaciones entre el autor y la escritura: y la certeza de su existencia en cualquier ámbito del mundo donde se escoja la escritura como destino. ${ }^{3}$

Preocupación constante en la reflexión de este escritor cuyos trabajos teóricos apuntan una y otra vez a la necesidad de atender este aspecto fundamental de la creación literaria. En Narrativa: instrumental y observaciones, por ejemplo, Balza revisa los aportes importantes del arte novelesco del siglo XX: la importancia de la filosofía bergsoniana en la concepción del tiempo novelesco (Proust, Joyce, Faulkner); la importancia que toma el

${ }^{3}$ José Balza, "Un vínculo excitable”, El Nacional (Caracas, 3 de diciembre de 1980). 
espacio en la novela (Huxley, Dos Passos, Durrell): la influencia de la filosofía de las ciencias (física moderna) en el nouveau roman de Alain Robbe-Grillet. De esta revisión crítica surge la proposición de Balza —-su propia concepción novelesca-, la identificación del rol de la conciencia en el proceso del conocimiento y en la creación literaria:

Construir una novela para expresar la multiplicidad psicológica de un sujeto, significa realizar la descomposición dimensional de la personalidad de ese sujeto, dándosele igual jerarquía de realidad a sus actos, a su pensamiento, a su vida imaginaria y, hasta donde sea posible, a la vida ajena a su propia conciencia ... lo estructural se lograría en planos, en la dimensión psíquica del espacio. ${ }^{4}$

El espacio-visión, el tiempo-instante será el punto de vista narrativo escogido por este escritor. El monólogo interior mediante narración expresará adecuadamente las rupturas, los cambios de niveles. Para una mejor captación de la multiplicidad psíquica, la novela será de naturaleza analítica, conceptual, y la descripción se reducirá al máximo. La óptica novelesca es la de la mirada del hombre definiéndose por sus respuestas al mundo.

\section{DIVERGENCIAS CON EL NOUVEAU ROMAN}

El punto en el que Balza se aparta definitivamente de las propuestas del nouveau roman, y de Robbe-Grillet en particular con cuya obra mantiene un parentesco evidente, es en el de la creación de personajes con una expresión analítica que acompañe su percepción sensorial. Para Balza el rol de la conciencia es imprescindible en la concepción del personaje novelesco. La naturaleza de la conciencia humana es primordialmente psicológica para él. Su postura refleja el deseo de recortar la distancia entre lo afectivo y lo objetivo y sitúa su trabajo en una posición fundamentalmente distinta a la del nouveau roman. El personaje de Balza será un hombre desprendido del mundo, un ser contingente en lo posible pero no por eso incoherente. Por imprecisos que sean los lugares o momentos en que se desenvuelve, habrá siempre una realidad concreta que es la de su discurso reflexivo, hilo conductor de ese mundo interior. "Quisiera que los personajes existieran por su pensamiento (pensar es el único acto)", dice el narrador de $\mathrm{D}$, $\mathrm{y}$ en las novelas de Balza la única realidad es la del pensamiento.

\section{EL MÉTODO}

Si la mirada de la conciencia sobre sí misma - la introspección - es el mecanismo que opera en toda construcción literaria, una introspección pura es la que Balza propone como método para explorar su mundo psíquico. Así el objeto literario surge de la experiencia existencial más inmediata y no pierde por lo tanto su calidad de sujeto. el punto de vista es el de la inmediatez de una conciencia y allí el escritor logra conciliar los extremos entre una realidad exterior amenazadora y una realidad interior auténtica. La perspectiva señalada por Balza tendrá como consecuencia el acercamiento entre el hombre y el mundo. Escritura

\footnotetext{
${ }^{4}$ José Balza, Narrativa: instrumental y observaciones (Caracas: Universidad Central de Ve-nezuela, 1969) 28.
} 
que se instaura como tentativa por resolver el malentendido entre objeto y sujeto. El epígrafe de Narrativa (tomado de Sartre) refuerza el carácter fenomenológico del trabajo de Balza:

... me he refugiado en aquella zona neutra y común que no es absolutamente lo objetivo -ya que, en fin de cuentas, me mantengo allí por propia voluntad - no lo absolutamente subjetivo - ya que todo el mundo me puede alcanzar allí, y allí encontrarse consigo mismo-, pero que podría denominarse a la vez la subjetividad de lo objetivo y la objetividad de los subjetivo.

\section{UNA TEORÍA DE LA NOVELA}

Las observaciones de este escritor, su proyecto concreto de escritura, son el resultado de una determinada concepción de la novela. El género novelesco surgiría para él a raíz de la distinción que hace el individuo en un momento dado de la historia entre su conciencia intelectiva y su conciencia emotiva. El fenómeno que explica esta aparición sería el descubrimiento y la aceptación de lo irracional en la mente humana. La novela tendría así un origen metafísico e ilustraría el proceso de conocimiento en el individuo moderno ya que responde a una necesidad de aprehender el mundo en su totalidad. La función específica del novelista es entonces la de trabajar en la formación de su propia existencia. El objetivo de la actividad literaria ya no es informar sobre el mundo sino contribuir a forjarlo. De allí el compromiso ahora ineluctable entre arte y vida que Balza vierte en ejercicios que atañen tanto lo existencial como lo literario. Así lo expresa el narrador de Largo:

He aquí que reviso mi vida, que anulo hechos y origino nuevas consecuencias de causas que no fueron tales; he aquí que rescato mi propia existencia y descubro que no sólo puedo entender como objetos a los demás sino a mí también; y aun, que puedo ser un objeto inventado. ${ }^{5}$

\section{MARZO ANTERIOR: UNA LECTURA}

Adentrarnos más concretamente en la novelística de José Balza justifica la escogencia de una de sus novelas, Marzo anterior, que permitirá constatar la articulación de los aspectos teóricos señalados. Primera novela de este escritor, Marzo anterior contiene elementos fundamentales que su obra posterior desarrollará: aquí se abren caminos determinantes en la búsqueda de esta escritura. Germinal en cuanto a perspectiva y contenido narrativos, Marzo anterior se erige en proyecto de una obra que acepta el reto de crecer hacia sí misma: Largo, Setecientas palmeras, $D$ y Percusión completan, amplían y multiplican las líneas esbozadas por aquélla. Como dice el mismo Balza:

Esa advertencia (o descubrimiento) de la escritura propia de un autor sólo posee un valor: afinarnos para vislumbrar (o para reconocer, al fin) la palabra última del escritor; porque

\footnotetext{
${ }^{5}$ José Balza, Largo (Caracas: Monte Ávila, 1968) 93.
} 
en síntesis todo creador propone únicamente una palabra en su obra a pesar de los diversos libros que escriba: los libros dan el sentido exacto de esa palabra. ${ }^{6}$

Marzo anterior tiene como marco la constante proximidad-real o imaginariadel río. Aquí la imagen que cobra el río mantiene sus atributos tradicionales, a saber: la transformación, la renovación continua, lo efímero. Marzo anterior es la novela de la vida humana en su dualidad físico-psíquica, en su inútil lucha contra el tiempo, en su búsqueda -destinada al fracaso- de un absoluto cualquiera. El río, la multiplicidad, el cambio, son términos diferentes para expresar esta realidad de la condición humana. Pero esta novela es también la novela de la escritura; el viaje, la huida y la espiral hablan de la aventura de la palabra que lanza al hombre a través de espacios interiores, tras una coherencia que toma la forma elusiva del tiempo y que sólo un proyecto de escritura puede realizar. Veamos en que consiste este proyecto.

El narrador de Marzo anterior comparte con el lector la inmediatez de sus percepciones y pensamientos. El lector se ve sumergido en la atmósfera creada por una conciencia analítica y a la vez perceptiva. El relato se teje en base al monólogo de la conciencia que cuenta los hechos que la ocupan y las reflexiones que estos hechos despiertan en ella. El narrador se define, se construye frente al lector mediante sus respuestas frente al mundo. La conciencia del lector coincide con la del narrador en esta perspectiva narrativa: se podría decir que el lector se confunde con este narrador-personaje en cuanto que juntos descubren la realidad. El relato surge de un presente desprovisto de explicaciones tradicionales; el lector no sabe quién habla, dónde se sitúa la acción ni de qué se trata exactamente.

La mirada del narrador en pugna con lo real traza la evolución del relato y al mismo tiempo dibuja al narrador. En Marzo anterior la mirada del narrador es estructurante en cuanto refleja una visión doble de la realidad y urde de esta manera el tema de la novela que es la multiplicidad de la conciencia. El narrador se perfila a través de pensamientos, de miradas; se va afianzando a medida que responde a lo real. El narrador es la suma de los diversos puntos de vista que coexisten en él: el adolescente, el adulto. Cada experiencia tiene un valor absoluto ya que se impone a la conciencia negando cualquier otra realidad; a esto se debe que cada secuencia sea independiente de las demás. El narrador se expresa en lo instantáneo. Para Balza, como para muchos escritores del siglo XX, la única realidad accesible al hombre es la del aquí y el ahora, y la profundidad - si es que existe- es aprehensible sólo a través de lo actual, del presente, del espacio. Marzo anterior niega la continuidad, la historicidad de la conciencia humana. Por el contrario la conciencia está hecha de momentos discontinuos que la asaltan y la reclaman por entero. Estos momentos puntuales configuran los espacios de la novela.

La historicidad de la novela se construye a posteriori cuando los pedazos aparentemente dispersos cobran perspectiva en el relato. A medida que avanza el relato, las secuencias empiezan a establecer entre sí relaciones de identidad y diferencia. El lector intuye el contorno del narrador sin precisarlo por completo; las significaciones son sugeridas

${ }^{6}$ José Balza, Los cuerpos del sueño (Caracas: Universidad Central de Venezuela, 1976) 13. 
más que afirmadas. El movimiento del relato conserva un carácter de incertidumbre: ¿Aníbal y Logzano son la misma persona? ¿El pueblo y la ciudad son el mismo lugar? La indecisión es inherente a los fenómenos de percepción porque ya no hay mediaciones psicológicas en la novela: hay sólo la descripción de los aspectos inmediatos de una vida psicológica. De allí que cada secuencia sea radical en relación a las demás porque toda percepción es real mientras ocupa la conciencia. El carácter irreal de la novela se debe al hecho de que cada certeza en el relato es destruida por la siguiente. El personaje-narrador ya no es una totalidad. El lector debe intervenir en el espectáculo que se presenta frente a él.

El hombre de Balza rehusa instalarse en el ser, en la duración. La noción de tiempo tradicional se suprime y todo se reduce a la presencia en el espacio. Se presentan fenómenos discontinuos. En Marzo anterior la noción de personalidad tradicional es abolida ya que no hay distinción rígida entre lo pasado, lo presente y lo imaginado. Balza no cree en la continuidad: el hombre está hecho de retazos de tiempo, de fisuras. El personaje-narrador describe con precisión lo que ve, lo que hace, pero no sabemos si el registro es real o imaginario. El exterior pasa por su mirada. La creación de lo real le corresponde a la mirada. En Marzo anterior se dibujan dos visiones diferentes de la realidad, por lo tanto se distinguen dos narradores en el relato. Cada uno de estos narradores crea su propia visión del mundo; cada uno de ellos arma una realidad según las imágenes inmediatas de una conciencia. A medida que avanza el relato las dos miradas se acercan, se completan para reconocerse una sola - aunque escindida - mirada. Este programa se anuncia desde la primera secuencia:

Dos bosquejos entre los cuales habría de estar situado realmente, único; pero a los que de antemano considero falsos aunque, tal vez, eso sí, menos falsos que mi propia anatomía, que mi pensamiento en esos encuentros. Porque habrá una negación en cada imagen respecto a las otras: el tiempo anterior las impulsará a anularse. Dentro del vértigo quedaré yo y tampoco tendré valor para reconocerme, para despejar la urdimbre de tales sombras imaginarias, puesto que cada una de ellas ocupará una parte de mi afectividad. ${ }^{7}$

En Marzo anterior coexisten realidades creadas por la mirada de un hombre que responden a diferentes situaciones en el tiempo y el espacio: es así como en la novela el amor visto por un adolescente convive con la visión amorosa del adulto. La forma de la novela depende estrechamente de la conciencia humana, por lo tanto el cuerpo novelesco no puede ser preestablecido puesto que descansa sobre los procesos de la conciencia y éstos son, ante todo, asociativos. No hay orden preconcebido en el universo; sólo una conciencia narrativa y, a la vez, estructura esta conciencia. Así la forma novelesca está sometida al punto de vista. En Marzo anterior la cronología no tiene ninguna importancia; la novela se construye siguiendo las prioridades afectivas de una conciencia narrativa. El lector puede trazar la línea de los acontecimientos "reales" de la novela - varios días entre la fuga imaginaria de Logzano y las reflexiones de la última secuencia- pero entre estos límites se intercalan otros acontecimientos tan reales como los primeros aunque de otro

\footnotetext{
${ }^{7}$ José Balza, Marzo anterior 11.
} 
orden. El lector tiene que estar sumergido en la narración para captar las relaciones entre los acontecimientos, para reconstruir el tiempo propio de esta conciencia.

El personaje se articula tomando conciencia de los elementos extraños que lo rodean. En Marzo anterior cada narrador se construye a través de su discurso reflexivo sobre el mundo. Los objetos estimulan la psicología del personaje quien, por medio de sus respuestas, se define, se describe. Balza considera sin embargo que es incorrecto pensar que los objetos crean al personaje. La pureza del personaje es una necesidad, el anonimato, también; pero este escritor parte de la noción de que la libertad del personaje no lo priva de reflexión. Aunque diga "yo", no se trata de un personaje tradicional. Marzo anterior no es una novela psicológica. Este yo está anclado en la contingencia, está escindido, hecho de ausencias y de rupturas. Su existencia no es por ello puramente perceptiva, sensorial. Tiene la libertad de pensarse a sí mismo como un ser singular. Así se conserva la profundidad humana; no hay separación entre lo profundo y lo humano.

Aun cuando el narrador recurre al monólogo interior indirecto (en forma de narración), no se puede hablar de una evolución o de una causalidad en él. Se trata sin duda de un personaje con un discurso consciente pero esencialmente solicitado por la inmediatez. La profundidad (nombre, pasado, historia) no es un a priori en el relato: el narrador dibuja progresivamente su profundidad mediante la utilización perceptiva de lo real. Aníbal contrasta con Logzano y viceversa. La dimensión de profundidad se desprende poco a poco del relato: las secuencias ensamblan una realidad de caras múltiples.

Para Balza es imposible tratar de expresar la aventura del hombre en el mundo con un personaje "ausente". La única realidad posible es la de la subjetividad y ésta existe en tanto que se distingue de lo que ella no es: lo objetivo. En este reconocimiento de sí el hombre tiene la certeza de su existencia. Y todo este proceso (¿cómo llegar a lo accesible para el hombre? ¿qué conocimiento es posible?) es el que introduce Marzo anterior. Aunque el discurso subjetivo no es nunca la persona, aquí permite aproximarse a ella mostrándola inacabada, fugaz, contradictoria.

En la novela de Balza es justamente el discurso lo que reduce la distancia entre lo objetivo y lo afectivo. Si Balza conserva el aspecto analítico de la conciencia, no podemos sino aferrarnos a las palabras para intentar reconstruir a la persona. El lenguaje/pensamiento del narrador es el soporte del relato aun cuando nunca será definitivo ya que constantemente se cuestiona, contradice o desmiente. En la mirada del narrador sobre sí mismo se esboza un posible, imaginario e incierto relato.

El personaje de Marzo anterior existe en su incertidumbre. No es la existencia la que está cuestionada sino su aspecto único y definitivo, la nitidez de sus percepciones. Aboliendo la causalidad, la continuidad psicológica, y presentando fenómenos discontinuos, Balza no suprime por ello la instrospección. No niega la interioridad aun cuando en Marzo anterior no hay tiempo interior: hay espacios psicológicos interiores.

Balza conparte con el realismo moderno la importanica de las percepciones concretas y materiales en la constitución de lo real, pero concibe la percepción como el punto de encuentro de una objetividad y de una subjetividad. Por lo tanto estas percepciones se acompañan necesariamente de las reflexiones que ellas propician. El río, las piedras, los demás, todo es motivo de reflexión para el narrador; y estas reflexiones sobre los objetos que lo rodean le dan una forma. 
Todos los niveles de la existencia coexisten en la percepción. En Marzo anterior se enfrentan dos miradas, dos realidades, dos narradores que el relato nos mostrará no obstante como una sola persona. Cada secuencia responde a un espacio psíquico del narrador y mantiene su independencia frente a las demás secuencias, pero lo importante para Balza es que el personaje tenga un acercamiento reflexivo a la realidad aunque la relación entre las secuencias no haya sido establecida de antemano. A cada corte espacial corresponde una forma de sensibilidad, una forma de conciencia. La continuidad entre los niveles no existe pero el personaje se reconoce en cada uno de esos niveles de existencia que lo caracterizan.

Cada segmento de la novela es un presente siempre actual. Si hubiese utilizado los recuerdos, el narrador reflejaría una coherencia, una totalidad propias de los personajes tradicionales. Traduciría el sentimiento de una continuidad anímica que justamente es negada aquí, ya que está por ser fundada. Hubao que desplegar en el espacio situaciones múltiples y a veces contradictorias para que se estableciera entre ellas una línea insegura, imprecisa, que define poco a poco el contorno del narrador. La significación debe surgir del trabajo que realiza el personaje-narrador sobre el mundo. La novela se construye frente a nosotros.

La realidad novelesca se disuelve porque la personalidad está disuelta: no hay rostro único. De allí que la novela finalice cuando el narrador se reconoce en la multiplicidad, cuando el yo, la comunicación o la acción se vislumbran como realidades posibles. La novela no quiere abordar un destino sino al contrario seguir el traycto de una conciencia antes de que una significación externa la recupere. Cuando el narrador acepte reconocer su pasado, ya no se sentirá desplazado por él; podrá entonces pasar a otra cosa. "Marzo anterior" ya no existirá pues se habrá resuelto en su interior. Hablar de un final sería darle un carácter definitivo a lo que podría ser un simple momento más en una experiencia humana y novelesca que se ha mostrado hasta ahora -cuando menos-insegura. Más que conclusión, la última secuencia se presenta como una vuelta de la espiral donde el narrador se descubre como la suma de las experiencias vividas. De hecho desde el principio de la novela había anunciado: "En el fondo ni siquiera esto es válido, porque en alguna vuelta de la espiral volveré a encontrarme yo mismo ante mí". ${ }^{8}$

El rostro, la persona, la forma de la novela están hechos de una materia frágil a punto de derrumbarse en todo momento. El final de la novela encierra el regreso al mismo punto de la espiral, pero el equilibrio consiguiento no puede ser sino precario. Marzo anterior dibuja el círculo recorrido por los desplazamientos interiores del narrador para volver al punto de tensión que permite el examen lúcido de esta experiencia.

El trayecto seguido es sin duda un trayecto circular hecho del vaivén entre pasado y presente, ciudad y pueblo, Aníbal y Logzano. La naturaleza de esta experiencia queda explicitada a lo largo del relato: "Y sé, no obstante, que este camino es un círculo", dice Logzano. Pero las vueltas pueden ser infinitas en la espera de una respuesta que no será nunca definitiva. El mundo ambiguo y dudoso que se erige y se derrumba sucesivamente es la negación de toda palabra fija. Marzo anterior no propone una significación acabada. Las múltiples secuencias que se identifican y se oponen, presentan la dificultad de una escritura lineal frente al problema de la conciencia humana. La percepción es

\footnotetext{
${ }^{8}$ José Balza, Marzo anterior 11.
} 
inevitablemente relativa y por lo tanto inestable, y la escritura que intenta describirla necesita ser igualmente experimental. En Marzo anterior las relaciones que se establecen entre los hechos son constantemente cuestionadas como si el orden contra el cual se atenta fuese siempre fruto del azar y no de la necesidad.

El vínculo nace de acuerdo a mis necesidades; por lo tanto, es falso y su sentido, variable. Nada tiene que ver con nada; no hay que temerle al caos y, sin embargo, es obsesiva, en todos, la delimitación de los niveles. ${ }^{9}$

Es cierto que la incógnita de la novela se aclara progresivamente, es cierto que el relato cumple un círculo en la búsqueda de identidad del narrador; sin embargo Marzo anterior conserva su carácter de ejercicio, de fenómeno. En este sentido parece incorrecto hablar de una resolución, de una totalidad. Se puede más bien hablar de un instante de reposo, de un momento de equilibrio que se impone, pero más allá del cual no hay nada previsible. Los trazos que se dibujan sobre el plan del libro tienen movimientos contradictorios: avanzan, retroceden, se desvían y regresan al punto de partida. Parecen ejecutar movimientos irregulares alrededor de un eje que también burla la inmovilidad. Intento de fusión entre una estructura literaria y una psíquica, las diversas secuencias apuntan al problema de las múltiples conjeturas que se presentan a la conciencia. La estructura de la novela sugiere la mente humana con su negación de secuencias lógicas. Mundo caótico hecho sobre todo de sensaciones independientes difíciles de sobrepasar. La novela tiende hacia esa superación: sobreponerse al espacio más allá de las rupturas. También nos demuestra que lo que parece logro, rara vez lo es por mucho tiempo:

Pienso que la felicidad existe cuando prevalece el espacio: las relaciones de los objetos o de los seres, despojados de condiciones temporales originan la ternura, la felicidad. No interesa entonces nuestro trancurso. En cambio cuando entre el tiempo, es porque sufro. ${ }^{10}$

Aun cuando el final de la novela sugiere la duración, la conciencia de sí sin distinción entre estados diferentes, Marzo anterior no es una novela del hombre interior. La duración es la conciencia del movimiento interior que unifica todo extremo: pasado y presente integran un todo orgánico. Es gracias al recuerdo que el espíritu toma conciencia de sí. Al extremo opuesto del recuerdo se encuentra la percepción. En Marzo anterior el narrador no recurre conscientemente al recuerdo. Cada secuencia de la novela corresponde a una percepción independiente. La percepción sitúa al individuo fuera de sí mismo. No lo construye un movimiento continuo sino una sucesión de estados independientes. El tiempo es experimentado aquí como realidad exterior; de allí que se traduzca en una serie de cortes espaciales sin relación entre sí. El individuo está presente en el espacio y no en el tiempo. El tiempo del narrador es un tiempo constituido por sucesivas existencias en el espacio. Lo que resalta de esta elaboración novelesca es la preponderancia de los fenómenos de percepción y su carácter de incertidumbre. El hombre está condenado a buscarse en

\footnotetext{
9 José Balza, Marzo anterior 63.

${ }^{10}$ José Balza, Marzo anterior 145.
} 
miradas siempre actuales sobre la realidad; se define en este incesante intento por encontrarse. El hombre toma cuerpo en la multiplicidad que lo caracteriza. El narrador se perfila a través de los cortes psíquicos, en la estructura novelesca:

Soy libre si resumo mi existencia a este simple cuerpo, a sus sentimientos. Yo soy Aníbal o Logzano, una síntesis; todas las imágenes se agrupan con violencia. No me divido, me recobro. Y aquí está la salvación .... Marzo me construye, me indica que será suficiente con integrar las vivencias para volvera a empezar. ${ }^{11}$

Existir en el espacio imaginado, no obstante, el tiempo que unifica: ésta es la lucha instaurada por la conciencia que la forma de la novela traduce. Libertad humana y novelesca parece ser la impronta de Marzo anterior. Ni el hombre ni la novela tiene ya una verdad que proponer. La novela es una tentativa por darle sentido al caos, por establecer límites que sin embargo ella misma reconoce inciertos y relativos.

\section{LO OTRO}

La lectura de Marzo anterior arroja luz sobre una vertiente fundamental de la novelística de José Balza que es la de ser una escritura de la multiplicidad psíquica. En efecto, desdoblamientos y trasmutaciones acompañan a los narradores de todas sus novelas como si la única manera de acercarse a la persona fuese a través de las máscaras que la descomponen y que en el fondo, en vez de ocultarla, lo que hacen es reflejarla con aún más exactitud. Este deseo de proyectarse en lo exterior, de objetivarse, llevará al escritor a su definición más precisa: "sólo a fuerza de ser lo otro se puede ser único", dice Balza en unas reflexiones sobre lectura y crítica. En el mismo sentido, en Narrativa descompone el mito de Narciso para mostrar la estrecha correlación entre la imagen del joven griego ensimismado y el conocimiento humano: la mirada debe escindirse, multiplicarse para aspirar a la unidad. Son esas refracciones las que pueblan los mundos imaginarios de Balza: ser uno mismo y a un tiempo ser otro; ser todos y quizás ninguno en el fondo. La única verdad posible es el propio reflejo tembloroso, el abismo interior donde el vértigo rehusa detenerse:

... hasta que otro individuo acepte ser él mismo y ser otro en su propia conciencia ... ${ }^{12}$

... en cada segmento estaba la huella de una proposición: rasgar lo cotidiano, extender las fugaces vibraciones del pensamiento y de la sensibilidad: quería ser otro. ${ }^{13}$

Así quiero escribir, como si la historia fura de los otros (y observada desde ese punto de vista), o de los demás y al final mía ... ${ }^{14}$

\footnotetext{
11 José Balza, Marzo anterior 153.

12 José Balza, Largo 139.

${ }^{13}$ Setecientas palmeras plantadas en el mismo lugar (Caracas: Sítesis Dosmil, 1974) 156.

${ }^{14} D$ (Caracas: Monte Ávila Editores, 1977) 265.
} 
... comienzo realmente a ser tú -yo mismo, otra vez joven - y lo único que puedo ofrecerte es la fábula en que todavía me reconozco: las imágenes de mi existencia. ${ }^{15}$

\section{LA LUCIDEZ}

Llegamos así a otra de las constantes en la escritura de Balza, el valor absoluto asignado al pensamiento en la elaboración de la realidad. Los personajes están fatalmente llevados por su inteligencia a organizar e interpretar los hechos que viven. Es ineludible en ellos la necesidad de ordenar lo aparentemente fragmentario, de atravesar con su mirada analítica lo informe, lo caótico; porque no hay tarea más impostergable para la conciencia que la de infundir sentido y crear así su propia coherencia. Proyecto de salvación, esta lucidez es sin embargo una condena que se interpone entre el hombre y su completa realización ya que lo remite constantemente a su naturaleza dual, a la falta de coincidencia entre él y el mundo. Sin embargo le permite con el tiempo rehacer el camino entre una aprehensión individual del mundo y una realidad móvil y huidiza. La historia del hombre no puede ser negada pero es posible conjurar el sentido de sus atributos para intentar recobrar la inocencia y la frescura olvidadas. En este sentido la lógica ya no debe operar en base a un pensamiento abstracto que inmoviliza al hombre. Se impone el abandono de relaciones mentales que impiden arrostrar la realidad con una actitud libre y desprejuiciada. El pensamiento es el instrumento para esto pero sin duda debe doblegarse para permitir esta nueva concepción de las cosas que surge de su dinamismo interior. El narrador de Percusión, al volver a su tierra después de muchos años de ausencia, justifica así esa tendencia por asumir la movilidad de la vida:

Pero cuando vi casarse a mis amigos, cuando noté que todos tendían a fijarse en cualquier grupo - matrimonio, oficinas, partidos políticos-acepté con cierto horror que yo estaba obsesionado por ser transitorio, por aspirar todas las incertidumbres. Ahora reconozco que mi maldición tenía un nombre: el impulso de entender. Únicamente la más intensa cópula ha sido comparable - para mí- con las milagrosas escalinatas del pensamiento. Saber: allí residía el peso que me arrastraba de un ser al nuevo, de un sabor al otro, de un continente a inesperadas oscuridades geográficas. ${ }^{16}$

\section{UN CONTENIDO EXISTENCIAL}

Como hemos visto la obra de José Balza atribuye una importancia notable a problemas tales como la libertad, la alienación, la autenticidad, la relación con el mundo. Son novelas cuyos personajes tienen una carga considerable de preocupación existencial que enfrentan en una atmósfera donde subsiste un sentimiento de fragmentación. Se aborda el problema del sujeto pensante pero también sensible y con capacidad de actuar. Tanto la razón como los sentimientos y el cuerpo manifiestan la existencia de estos seres. La novela aborda la significación de la existencia humana en lo que tiene de concreto, y los obstáculos y

\footnotetext{
${ }^{15}$ Percusión (Barcelona: Seix Barral, 1982) 13.

${ }^{16}$ Percusión (Barcelona: Seix Barral, 1982) 18.
} 
frustraciones que encuentra. A pesar de la insistencia en la subjetividad, no se propone un acercamiento idealista del mundo. El mundo existe porque encuentra un mundo real (tanto material como humano) pero a su vez este mundo no podría existir sin una mirada humana que lo reconociera. La novela representa la lucha del hombre por llegar a ser plenamente en un mundo que ofrece una resistencia.

La escritura de Balza propone la existencia del individuo como la posibilidad de reflexionar sobre sí, de pensar en lo que es y en lo que desearía ser. La existencia del hombre está dada por este trabajo de introspección que él realiza sobre sí mismo. La naturaleza humana es por lo tanto dinámica y se define por el movimiento constante que lleva al ser humano a trascender siempre el momento presente. La novela presenta al individuo con lo que tiene de incompleto, de inacabado. En la búsqueda de sí que caracteriza su vida, la descripción del hombre remite lógicamente a posibilidades más que a propiedades.

Con Balza la novela muestra también la búsqueda de una temporalidad humana. Sus narradores manifiestan el deseo de integrar diferentes dimensiones temporales de su vida para sobreponerse al desequilibrio causado por momentos aparentemente dislocados. La novela expresa el anhelo del individuo de recuperarse recreando un tiempo humano. En estas novelas el problema del conocimiento aparece íntimamente ligado al de la existencia. Existir (distinguirse de lo otro) es conocer. El individuo existe porque toma conciencia de sus relaciones con los demás (a veces consigo mismo) y con la realidad. El mundo le está dado como materia bruta pero el individuo establece una red de referencias que le permite asignarle un sentido a las cosas. Los personajes de Balza sienten la necesidad de integrar las diversas facetas que componen su vida. Toda verdad surge así de las profundidades de la existencia y no de la objetividad o de la subjetividad absolutas. el pensamiento no puede ignorar el proceso existencial, lo que la vida tiene de concreto y temporal.

Todos los aspectos abordados en este estudio apuntan a revelar la naturaleza particular de la novelística de José Balza. Se trata evidentemente de un escritor para quien la creación literaria es el campo de fuerzas donde se juega su propia vida. El compromiso absoluto con la escritura lo lleva a buscar su material en la realidad más inmediata a su alcance. El objeto de esta literatura es por lo tanto el proceso mismo que la hace existir. Esta manera de situarse con respecto a sí mismo le da a sus escritos un dinamismo evidente. De allí la necesidad que siente de hablar de "ejercicios", ya que la palabra "novela" no sirve siempre para traducir esta complejidad. La escritura considerada como una arma del conocimiento derrumba toda posible barrera entre poesía y verdad. Aquí la creación no es una simple realización estética: forma parte integral del mundo espiritual del hombre. En vez de ser reflejo de la realidad, el arte se erige en proceso mental; la novela ya no es un producto sino un medio en la tarea de definir la naturaleza y los límites del conocimiento humano. 
